\title{
RESENHA
}

\section{FERREIRA, E. \& OLIVEIRA, D. A. Crise da Escola e Políticas Educativas. Belo Horizonte: Autêntica, 2009.}

\author{
Por Marilene Zampiri
}

\begin{abstract}
A presente obra propõe um aprofundamento do debate que cerca os problemas que perpassam a oferta educacional pública, tendo como referência a acessibilidade a um direito tido como universal, fazendo uma relação deste com as políticas educativas propostas para este fim, e das quais a escola, como espaço privilegiado da execução e concreção da ação educativa, não passa incólume. Ao contrário, o texto revela o tamanho da crise que a escola se depara especialmente quando se trata da execução de sua função social.
\end{abstract}

Inicialmente as organizadoras estabelecem as âncoras que sustentam o debate. Assim alguns autores são chamados a levantar os marcos conceituais desta matéria de indiscutível relevância social, mas que por ainda não estar completamente efetivada como direito de todos, situa-se em permanente campo de conflito e conseqüentemente de disputa e, por esta razão, reclama do leitor e pesquisador uma tomada de posição ou uma localização intelectual e política sobre a matéria. Assim, é forçoso que se explicite o que pode e deve ser assumido como a efetivação do direito à educação de qualidade para todos.

Desta forma, na primeira parte do trabalho importantes conceitos são formulados e enfatizados os quais situam o leitor quanto aos limites e possibilidades das idéias contidas na obra. A primeira preocupação aponta as mudanças ocorridas em relação à função da escola, local privilegiado da concreção do ato educativo. Os textos assinalam uma duplicidade de função nas instituições escolares, ou seja, na contemporaneidade a escola assume também a função de promotora de justiça social, o que pode the conferir um peculiar caráter assistencial agregado à sua tradicional função de credenciar indivíduos a uma participação social ativa, por meio do acesso a um conjunto de conhecimentos considerados válidos. Éneste ponto que reside o problema: simultaneamente à ampliação ou ao alargamento das funções da escola percebe-se a coexistência de certa fragilização de suas funções primordiais. Neste sentido, disponibilizar o direito à educação de forma precária também não pode ser considerado socialmente justo mesmo que agora para todos ou para a maioria. É isso que as autoras denominam crise da escola. O primeiro capítulo é dedicado a discutir o que pode ser considerado como uma escola socialmente justa e como o conceito de justiça social vai sendo modelado a partir também de mudanças na dimensão de educação de qualidade.

A matéria é aprofundada no segundo capítulo, quando o autor, mesmo tendo como referência o contexto social e político francês, colabora no debate e mostra o limite da concepção de justiça social descrevendo o quanto esta deve às orientações econômicas na sua formulação e definição. Na mesma linha defendida pela autora do capítulo anterior, também sugere que a educação tornada direito de todos, trouxe para dentro da escola a diversidade e junto à reproblematização do conceito de justiça social e levanta a importante discussão acerca do limite entre o justo reconhecimento das diferenças e o necessário projeto coletivo, na perspectiva da construção de uma sociedade mais igualitária. A qualidade então passa a ser o critério de justiça social e transforma igualdade em equidade. 
Na seqüência, Frigoto conduz a discussão desta questão para o contexto social brasileiro e traz para o debate reflexões importantes sobre a formação social e econômica do país e em que proporção as políticas educacionais pode ser creditadas aos interesses da reorganização do capital nacional e internacional levando o autor a considerar uma possível regressão dos direitos sociais, entre eles a educação, como conseqüência destas influências. De certa forma também este autor percebe no atual contexto de formulação de políticas educacionais uma considerável perda do ideário societário alternativo capaz de minimizar as grandes desigualdades sociais.

Na verdade os três primeiros capítulos levam o leitor a refletir sobre o efeito que políticas educacionais fragmentadas, fortemente influenciadas pelos interesses das forças dominantes, produzem na concreção do ato educativo no interior da escola. Tais políticas sustentadas no princípio do reconhecimento das diferenças, mas que se levadas ao extremo podem provocar a perda ou precariedade de uma alternativa societária coletiva menos desigual e, portanto mais justa.

O problema das políticas públicas é que os destinatários destas, na maior parte das vezes, não participam ou influenciam muito pouco da sua proposição e formulação. O capitulo IV, fecha esta parte do livro, com uma importante e profunda reflexão sobre a origem e constituição do poder político em sociedades ocidentais caracterizadas por cisões sociais como ocorre no contexto brasileiro e ajuda a compreender as construções sociais que faculta a determinados sujeitos, possibilidades de decisão política em um dado contexto histórico.

Assim, esta parte da obra atualiza importantes e imprescindíveis bases conceituais que sustentam a pesquisa em políticas educacionais. Justiça social, direito à educação, poder político, Estado, políticas públicas, urdem um quadro referencial útil ao leitor e ao pesquisador na análise de políticas públicas em especial no campo do direito à educação.
Os próximos cinco capítulos do trabalho discorrem sobre os diferentes aspectos das circunstâncias onde e como são engendradas as políticas educativas, as quais as organizadoras denominam conjuntura.

Inicialmente, Cunha retoma o conceito de administração educacional zigue-zague para explicar a forma como são geradas as políticas educacionais no Brasil, ou seja, um padrão de ação ou atuação política administrativa presa a gestão de determinado governante, mudando de acordo com as mudanças do cenário político. O autor destaca os malefícios derivados desta forma de atuação política, especialmente quando se trata da disponibilização de um bem social como o direito à educação. É possível que a fragmentação, característica importante da produção de políticas públicas, já mencionada na primeira parte deste livro, possa ser explicada em parte por esta forma pouco eficaz e nada efetiva de produzir políticas públicas. Na verdade o texto de Cunha vem reforçar a idéia de que políticas educacionais devem ser políticas de Estado e não de governo.

De certa forma o capítulo subseqüente também faz menção ao modo de engendrar políticas educacionais, quando faz referência à tendência de aliar às práticas e políticas educacionais a racionalidade científica, algo já experimentado em outros campos de atuação, na medicina por exemplo. O capítulo discute a EBP (educação baseada na prova). Embora o texto trate de um contexto específico, o europeu, a EBP ao exigir a comprovação ou estudo como balizadores de políticas e práticas educacionais minimiza outras influências. A idéia de políticas comprovadamente eficientes requer monitoramento, tanto na produção das provas como na posterior execução. Nesta perspectiva a avaliação da efetivação de políticas torna-se componente essencial nos sistemas educacionais e este é um fato cada vez mais presente nos sistemas educacionais de vários países, inclusive no Brasil. O problema talvez seja a produção de provas 
e padrões que continua sendo disputado no campo político onde, como já mencionado em capítulos anteriores, os destinatários tem pouca ou nenhuma influência. Desta forma mesmo que a formulação de políticas públicas se caracterize por uma cientificidade o que lhe garante um grau considerável de autonomia, não está imune aos direcionamentos políticos, mesmo que apenas na sua origem, ou seja, são os sujeitos com poder político que influenciam a direção que pode tomar a modelagem de uma política pública. De qualquer forma o texto traz para o debate contribuições para analisar o contexto da produção de políticas educacionais.

Aindaconcernenteà conjuntura, os capítulos sete e oito tratam das influências externas na formulação de políticas educacionais. Mesmo alertando para os prejuízos advindos das influências de organismos internacionais ou externos que, em certa medida, forçam formulações de políticas educacionais nem sempre vinculados à disponibilização do direito à educação de qualidade para todos, parece que a internacionalização é uma tendência que tem tomado corpo na produção e formulação de tais políticas. No entanto, tal tendência apresenta também aspectos favoráveis dado que a formação de espaços regionais ou internacionais pode ampliar as possibilidades de práticas e políticas educacionais tendo em vista que a cooperação e a complementaridade na proposição de ações educativas podem resultar em benefícios recíprocos, constituindo-se em uma saída para superar os problemas enfrentados interna e localmente pelos países envolvidos. Ressalte-se, no entanto, a necessidade de preservar a autonomia, a cultura e os bens naturais e estratégicos locais, ou seja, é preciso que seja uma relação de cooperação de fato e não dominação ou subjugação. Assim, os textos alertam para a diferença entre a internacionalização solidária e a transnacionalização como forma de facilitar o estabelecimento de programas educacionais, fazendo de países periféricos filiais de centros industrializados.
Finalizando o conjunto de textos relativos à conjuntura, o capítulo dez salienta as mudanças que vem ocorrendo na Bolívia nos últimos anos especialmente no caso das reformas do campo da educação e o alcance que estas podem atingir. Neste caso tratase, de acordo com o texto, de um processo de descolonização no sentido de libertar - sistema educacional das estruturas de dominação colonial. Ocorre que, embora a iniciativa pareça interessante existe a possibilidade de políticas direcionadas para grupos específicos, neste caso para os indígenas, que mesmo sendo a maioria não se constitui na totalidade dos interesses do país. Isso que dizer que tais políticas podem resultar em políticas compensatórias e não integradoras como seria desejável. Assim, o processo de construção de uma ideologia e cultura local passa por uma recuperação da cultura usurpada sem desconsiderar o acervo cultural produzido, mesmo que sob jugo colonial, neste período histórico. Não se trata de substituir ou compensar grupos excluídos, mas de integrar a totalidade do sistema de forma a contribuir para a geração de alternativas sociais mais justas e solidárias.

Esta parte da obra revela-se especialmente proveitosa no sentido de não excluir da análise as influências internas e externas na modelagem das políticas educacionais, tendo como referência a educação de qualidade como direito universal de todos e um bem social público urdido a partir do quadro conceitual anteriormente discutido.

Desta forma a ciência deve indagar em que medida as políticas educacionais são pensadas, planejadas e avaliadas tendo como critérios a referência antes declarada e socialmente aceita. Dito de outra forma, qual a dimensão de qualidade intrínseca nas políticas educacionais apresentadas à sociedade. Será que, de fato, estas políticas apontam para a ampliação do direito social è educação ou tão somente atende as orientações do mercado? Ou ainda, talvez tais políticas guardem em si, as duas dimensões, mas alguma prevalece sobre a outra? 
Os capítulos finais da obra tentam dar pistas para a compreensão dos efeitos das políticas educacionais acenadas pela bandeira do direito à educação de qualidade para todos.

Neste sentido, Eliza B. Ferreira, alerta em primeiro lugar para o fato de que, embora a escola esteja em crise, pois não se constitui na promessa de mobilidade social, continua sendo via obrigatória da quase maioria da sociedade. Se isto é verdade, reitera-se a necessidade de curvar-se de forma ainda mais intensa e profunda no estudo e análise do percurso e efeitos das políticas educacionais e contribuir quem sabe para a mudança do itinerário destas na expectativa de ampliar o direito à educação de qualidade para todos.

A autora deste capítulo analisa as políticas educacionais nos dois últimos períodos históricos e afirma que o período que antecede o atual governo mostrou fortes características regulatórias onde o Estado fiscaliza a ação exercida pelos entes federados no sentido de cumprir um determinado plano educativo. Assevera também que a gestão educacional do atual governo, ainda que esteja longe de se constituir em um plano efetivo de emancipação social, deve ser reconhecido no mínimo como uma tentativa de corrigir distorções e constituir uma unidade nacional menos desigual.

Entretanto Marília Fonseca ao analisar alguns programas nacionais e a repercussão nas gestões escolares, conclui que a mobilização por meio de programas com intuito de melhorar as gestões de sistemas não obteve a ressonância esperada, acarretando mais em uma sobrecarga do que propriamente uma reorganização no âmbito escolar. Isto quer dizer que, não se pode pensar em planos de superação dos problemas nacionais da educação em a participação ativa e efetiva não só dos destinatários, mas dos profissionais que, como agentes intelectuais ativos, tem muito a contribuir na construção de uma escola de qualidade para todos.

Somente com a participação ativa de todos é possível tentar vencer a constante ameaça da vinculação da educação ao mercado, assunto tratado no ultimo capítulo, que relata como a adoção de uma pedagogia ou outra pode determinar o grau desta dependência.

Finalmente, o presente livro leva o leitor a acreditar que mesmo que a escola não forneça as condições efetivas para emancipação intelectual e técnica de todos os estudantes, necessárias para a superação das desigualdades sociais, ainda é o espaço social potencialmente e estrategicamente reconhecido para este fim. Portanto, é preciso mobilizar todos os esforços, incluindo todos os segmentos sociais, no sentido de articular um plano de ação e atuação política de Estado que congregue o reconhecimento da diversidade com a busca de uma unidade nacional da sociedade brasileira. 